\title{
The economic insurance value of ecosystem resilience
} Baumgärtner, Stefan; Strunz, Sebastian

\author{
Publication date: \\ 2009
}

\section{Document Version}

Publisher's PDF, also known as Version of record

Link to publication

Citation for pulished version (APA):

Baumgärtner, S., \& Strunz, S. (2009). The economic insurance value of ecosystem resilience. (Working paper series in economics; No. 132). Institut für Volkswirtschaftslehre der Universität Lüneburg.

\section{General rights}

Copyright and moral rights for the publications made accessible in the public portal are retained by the authors and/or other copyright owners and it is a condition of accessing publications that users recognise and abide by the legal requirements associated with these rights.

- Users may download and print one copy of any publication from the public portal for the purpose of private study or research.

- You may not further distribute the material or use it for any profit-making activity or commercial gain

- You may freely distribute the URL identifying the publication in the public portal ?

Take down policy

If you believe that this document breaches copyright please contact us providing details, and we will remove access to the work immediately and investigate your claim. 
The economic insurance value of ecosystem resilience

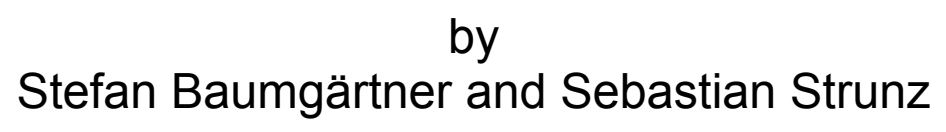

University of Lüneburg Working Paper Series in Economics

No. 132

July 2009

www.leuphana.de/vwl/papers

ISSN 1860 - 5508 


\title{
The economic insurance value of ecosystem resilience
}

\author{
Stefan Baumgärtner* and Sebastian Strunz \\ Department of Sustainability Sciences, \\ Leuphana University of Lüneburg, Germany
}

July 2009

\begin{abstract}
Ecosystem resilience, i.e. an ecosystem's ability to maintain its basic functions and controls under disturbances, is often interpreted as insurance: by decreasing the probability of future drops in the provision of ecosystem services, resilience insures risk-averse ecosystem users against potential welfare losses. Using a general and stringent definition of "insurance" and a simple ecological-economic model, we derive the economic insurance value of ecosystem resilience and study how it depends on ecosystem properties, economic context, and the ecosystem user's risk preferences. We show that (i) the insurance value of resilience is negative (positive) for low (high) levels of resilience, (ii) it increases with the level of resilience, and (iii) it is one additive component of the total economic value of resilience.
\end{abstract}

JEL-Classification: Q57, Q56, D81, G22

Keywords: ecosystem, economic value, insurance, resilience, risk, risk preferences

\footnotetext{
*Corresponding author: Department of Sustainability Sciences, Leuphana University of Lüneburg, P.O. Box 2440, D-21314 Lüneburg, Germany, phone: +49.4131.677-2600, fax: +49.4131.677-1381, email: baumgaertner@uni-lueneburg.de, http://www.leuphana.de/seg.
} 


\section{Introduction}

Ecosystems that are used and managed by humans for the ecosystem services they provide may exhibit multiple stability domains ("basins of attraction") that differ in fundamental system structure and behavior. As a result of exogenous natural disturbances or human management, a system may flip from one stability domain into another one with different basic functions and controls (Holling 1973, Levin et al. 1998, Scheffer et al. 2001). As a consequence, also the level, composition and quality of ecosystem services may abruptly and irreversibly change. Examples encompass a diverse set of ecosystem types that are highly relevant for economic use, such as boreal forests, semiarid rangelands, wetlands, shallow lakes, coral reefs, or high-seas fisheries (Gunderson and Pritchard 2002).

The term "resilience" has been used to denote an ecosystem's ability to maintain its basic functions and controls under disturbances (Holling 1973, Carpenter et al. 2001). The economic relevance of ecosystem resilience is obvious, as a system flip may entail huge welfare losses. ${ }^{1}$ For example, a combination of drought, fire and ill-adapted livestock grazing management in sub-Saharan Africa, central Asia and Australia have lead to severe degradation and desertification of semi-arid rangelands, which provide subsistence livelihood for more than one billion people worldwide. Once degraded, these grassland ecosystems cannot be used as pasture anymore (Perrings and Walker 1995, Perrings and Stern 2000). In Africa alone, almost $75 \%$ of semi-arid regions are threatened by degradation and desertification (UNO 2002). Worldwide, the income loss associated with desertification of agricultural land is estimated to some 42 billion US dollars per year (UNCCD 2005).

An ecosystem's resilience in a given stability domain can be measured by the probability that exogenous perturbations make the system flip into another stability domain.

\footnotetext{
${ }^{1}$ Accordingly, some have included a reference to the provision of desired ecosystem services right into the definition of ecosystem resilience, e.g. as the capacity of an ecosystem "to maintain desired ecosystem services in the face of a fluctuating environment and human use" (Brand and Jax 2007: 3, referring to Folke et al. 2002).
} 
Therefore, enhancing the resilience of a particular (desired) domain reduces the likelihood of a flip into another (less desired) domain. It is for this reason that ecosystem resilience has been referred to as "insurance", e.g. in the following manner:

"Resilience can be regarded as an insurance against flips of the system into different basins of stability." (Mäler 2008: 17)

"[R]esilience $[\ldots]$ provides us with a kind of insurance against reaching a non-desired state." (Mäler et al. 2009: 48)

"The link between biodiversity, ecosystem resilience and insurance should now be transparent. [...] It follows that the value of biodiversity conservation lies in the value of that protection: the insurance it offers against catastrophic change." (Perrings 1995: 72)

"The resilience of the ecological system provides 'insurance' within which managers can affordably fail and learn while applying policies and practices."

(Holling et al. 2002: 415)

So far in the resilience literature, the term "insurance" is employed in a rather metaphoric manner - as a metaphor for "keeping an ecosystem in a desirable domain". It is used to convey the message that resilience is a desirable property of some ecosystem since it helps to prevent catastrophic and irreversible reductions in ecosystem service flows. While ecosystem resilience obviously and undoubtedly includes an insurance aspect, no explicit attempt has been made so far to use a clearly defined concept of "insurance" from the established literature on insurance and financial economics. As a result, it remains unclear what exactly constitutes the economic insurance value of ecosystem resilience, how it depends on ecosystem properties, economic context, and the ecosystem user's risk preferences, and how it relates to the total economic value of ecosystem resilience.

In an attempt to conceptually determine and to empirically capture the economic value of ecosystem resilience, Mäler et al. (2007) and Walker et al. (2007) have suggested 
to use the shadow price of resilience as a measure of its economic value. They calculate the present discounted value of future improvements in welfare from ecosystem services, where these future improvements accrue from reduced risks of a system flip due to a unit increase in the initial level of resilience. While this procedure establishes the total economic value of resilience, it does not explicitly relate it to any idea of "insurance".

In this paper, we aim to close that gap and to provide some conceptual clarification. Any idea of "insurance" fundamentally refers to a combination of three elements: (i) the objective characteristics of risk in terms of different possible states of nature, (ii) people's subjective risk preferences over these states, and (iii) a mechanism that allows mitigation of (i) in view of (ii). We believe that the ongoing discussion of resilience as an insurance could be clarified and fruitfully advanced if reference to these three elements was made explicitly and rigorously, and we propose an analytical framework for that purpose. We adopt a clear and generally accepted definition of "insurance" from the risk and finance literature, according to which insurance is an action or institution that mitigates the influence of uncertainty on a person's well-being (McCall 1987). Based on this definition, we conceptualize resilience's economic insurance value as the value of one very specific function of resilience: to reduce an ecosystem user's income risk from using ecosystem services under uncertainty. We also analyze how exactly the insurance value of ecosystem resilience depends on ecosystem properties, economic context, and on the ecosystem user's risk preferences.

Our analysis yields several interesting and important results. First, the insurance value of resilience is negative for low levels of resilience and positive for high levels of resilience. That is, ecosystem resilience actually functions as an economic insurance only at sufficiently high levels of resilience; it does not function as an economic insurance at low levels of resilience. Second, the (marginal) insurance value of resilience increases with the level of resilience - for some ecosystem types even monotonically. This is in contrast to normal economic goods, the (marginal) value of which decreases with their quantity. Third, the insurance value of resilience is one additive component of its total economic value. That is, the total economic value of resilience is larger than just its insurance value. While the latter may be negative, the total economic value of resilience 
turns out to be always positive.

The paper is organized as follows. In Section 2, we present a stylized model of an ecological-economic system that describes how different degrees of ecosystem resilience are related to different system outcomes, and how this contributes to an ecosystem user's well-being under uncertainty. In Section 3, we clarify what exactly we mean by "insurance" and "insurance value". On this basis, in Section 4, we present our results about the economic insurance value and the total value of ecosystem resilience, with all proofs and formal derivations contained in the Appendix. In Section 5, we discuss these findings and draw conclusions.

\section{Model}

To discuss the economic insurance value of ecosystem resilience, we propose the following simple and stylized model of an ecological-economic system. Consider an ecosystem that potentially exhibits two different stability domains with respective levels of ecosystem services-production. One domain is characterized by a high level of ecosystem service provision and corresponding net income $y_{H} \in Y$; the other domain is characterized by a low level of ecosystem service provision and corresponding net income $y_{L} \in Y$; with $Y \subseteq \mathbb{R}_{+}$and $y_{L}<y_{H}$, so that

$$
\Delta y:=y_{H}-y_{L}>0
$$

is the potential income loss when the system flips from the high-production into the low-production stability domain.

Initially, the ecosystem is in the high-production stability domain. In this domain, exogenous stochastic disturbances threaten to trigger a flip into the low-production stability domain. Such a flip may occur with probability $p$ with $0 \leq p \leq 1$. Conversely, the ecosystem stays in the high-production domain with probability $1-p$.

In line with Holling's (1973) notion of resilience as the maximum amount of disturbance a system can absorb in a given stability domain while still remaining in that stability domain, we define and measure resilience as a continuous state variable $R \in[0,1]$ 
that determines the probability of the system flipping from the high-production into the low-production stability domain as follows:

$$
\begin{gathered}
p=p(R) \quad \text { with } \quad p^{\prime}(R) \leq 0 \text { for all } R \text { and } p^{\prime}(R)<0 \text { for all } R \in(0,1) \\
\text { and } \quad p(0)=1, p(1)=0 .
\end{gathered}
$$

In words, the higher the ecosystem's resilience in the high-production domain, the lower the probability that it flips into the low-production domain due to exogenous disturbance; with zero resilience, it flips for sure; and with maximum resilience it will certainly not flip. For future reference, we define $\underline{R}$ through $p(\underline{R})=1 / 2$ as the level of resilience at which the probability of a system flip exactly equals the probability of the system not flipping. This is the level of resilience at which the future state of nature is maximally uncertain.

In order to give more ecological structure to our ecosystem model (2)-(3), in some parts of our analysis we assume the following more specific model about the relationship between the level of resilience $R$ and the flip probability $p$ :

$$
p(R)=1-R^{1-\sigma} \quad \text { with } \quad-\infty<\sigma<1 .
$$

This model has the fundamental resilience-defining properties (2) and (3). In addition, it has the analytically handsome property that $p^{\prime}(\cdot)$ is a constant-elasticity function of $R$, where the parameter $\sigma$ is the (constant) elasticity of $p^{\prime}(\cdot)^{2}$ i.e. $\sigma$ specifies by how much (in percent) the flip probability's slope increases when the level of resilience increases by $1 \%$. For short, we will refer to $\sigma$ as "the ecosystem's elasticity". As $\sigma$ may be positive or negative, one has 3

$$
p^{\prime \prime}(R)\left\{\begin{array}{c}
\geq \\
\overline{<}
\end{array}\right\} 0 \text { for all } R \in(0,1) \quad \text { if and only if } \quad \sigma\left\{\begin{array}{c}
\geq \\
\overline{<}
\end{array}\right\} 0 .
$$

Lacking ecological evidence or a plausible guess on the value of $\sigma$, we will study the full range of theoretically possible values of $\sigma$. Notwithstanding this generality, the

\footnotetext{
${ }^{2}$ Note that (4) implies $-p^{\prime \prime}(R) R / p^{\prime}(R)=\sigma$.

${ }^{3}$ For $\sigma=0, p^{\prime \prime}(R)=0$ holds also for $R=0$ and $R=1$. Yet, for $\sigma<0$, one has $p^{\prime \prime}(0)=0$, and for $\sigma \rightarrow 1$, one has $p^{\prime \prime}(1) \rightarrow 0$.
} 
case of $\sigma=0$ has an epistemically outstanding importance. For, one may argue that one can meaningfully define and measure the system's state variable "resilience" only through, and not independently of, the observable variable "flip probability". 4 Such an epistemic equivalence between the state variable $R$ and the observable $p$ is exactly what is expressed by $\sigma=0$. In this case, (4) reduces to a linear negative relationship, $p(R)=1-R$, so that resilience is measured directly in units of reduced flip-probability. As this case has an epistemically outstanding importance, we will treat the case of $\sigma=0$ as the preeminent case, and discuss the cases of $\sigma<0$ and $\sigma>0$ against it.

Given the ecosystem model (2), (3) - or, more specifically, model (4) - the ecosystem user thus faces a binary income lottery $\left\{y_{L}, y_{H} ; p(R),(1-p(R))\right\}$. That is, given that the system is initially in the high-production stability domain and is characterized by a level $R$ of resilience, the system will provide net income $y_{L}$ with probability $p(R)$ and net income $y_{H}$ with probability $1-p(R)$. Obviously, with changing level of resilience $R$ the statistical distribution of income will also change. As in our simple analytical framework only the level of resilience $R$ may vary, $R$ uniquely characterizes the income lottery. One may thus speak of "the income lottery $R$ ".

We assume that the ecosystem user only cares about (uncertain) income, and not directly about the underlying states of nature in terms of resilience. The ecosystem user's preferences over income lotteries are represented by a von Neumann-Morgenstern expected utility function

$$
U=\mathcal{E}_{R}[u(y)] \quad \text { with } \quad u^{\prime}(y)>0 \text { and } u^{\prime \prime}(y)<0 \text { for all } y,
$$

where $\mathcal{E}_{R}$ is the expectancy operator based on the probabilities of lottery $R, y$ is net

\footnotetext{
${ }^{4}$ If the system's state space was one-dimensional, one could indeed meaningfully define and measure the system's resilience (sensu Holling 1973) independently of the system's flip probability, namely as the "distance" in state space - measured in units of the single state variable - between the current system state and the threshold between stability domains. However, if the system is characterized by more than one state variable, the "distance" in state space is not uniquely defined but requires some metric which is not naturally given. Then, the system's resilience in a given stability domain cannot be measured through some distance in state space, but only through the observable consequence in terms of flip probability.
} 
income: ${ }^{5}$ and $u(y)$ is a continuous and differentiable Bernoulli utility function which is assumed to be increasing and strictly concave, i.e. the ecosystem user is non-satiated and risk averse. ${ }^{6}$ In order to study in the most simple way how the insurance value of resilience depends on the ecosystem user's degree of risk aversion, we assume that the ecosystem user is characterized by constant absolute risk aversion in the sense of Arrow (1965) and Pratt (1964), i.e. $-u^{\prime \prime}(y) / u^{\prime}(y) \equiv$ const., so that the Bernoulli utility $u(y)$ function is

$$
u(y)=-e^{-\rho y} \quad \text { with } \quad \rho>0
$$

where the parameter $\rho$ measures the ecosystem user's risk aversion.

\section{Conceptual clarification: insurance and insurance value}

Before we derive results about the economic insurance value of ecosystem resilience in the next section, in this section we provide exact definitions of the terms "insurance", "insurance value" and "total economic value". Adopting a very general and widely accepted definition, insurance may be defined in the following way (cf. McCall 1987).

\section{Definition 1}

Insurance is an action or institution that mitigates the influence of uncertainty on a person's well-being or on a firm's profitability.

In the concrete setting described in the previous section, the term "insurance" takes on a more concrete meaning. As a person's (here: the ecosystem user's) well-being is determined by a preference relation over income lotteries, insurance is about the

\footnotetext{
${ }^{5}$ For notational simplicity, $y$ denotes both the random variable income and income in a particular state of the world.

${ }^{6}$ While risk aversion is a natural and standard assumption for farm households (Besley 1995, Dasgupta 1993: Chapter 8), it appears as an induced property in the behavior of (farm) companies which are fundamentally risk neutral but act as if they were risk averse when facing e.g. external financing constraints or bankruptcy costs (Caillaud et al. 2000, Mayers and Smith 1990).
} 
mitigation of income uncertainty, and the person's risk preferences specify what changes in the income lottery actually constitute a "mitigation". Thereby, uncertainty exists due the existence of many potential future states of the world (here: high and low ecosystemservice production), in each of which the state-specific income is known $\left(y_{H}\right.$ and $\left.y_{L}\right)$ and the probability of which is also known $(1-p(R)$ and $p(R))$. That is, uncertainty comes in the form of risk in the sense of Knight (1921).

In this more concrete understanding of the term, insurance may come in many forms. One example is the classic insurance contract that an insuree signs with an insurance company under private law, and which specifies that the insuree pays an insurance premium to the insurance company in all states of the world and in exchange obtains from the insurance company an indemnification payment if and only if one particular unfavorable state of the world should occur. Another example is so-called "self-protection" (Ehrlich and Becker 1972), which means that a person undertakes some real action that reduces the probability by which an unfavorable - in terms of net income - state of the world occurs. In this terminology, an increase in the ecosystem's resilience by the manager may be interpreted as insurance because it is a real action that may provide self-protection in terms of net income obtained from the ecosystem.

In order to precisely define and measure the economic insurance value of some act of self-protection (here: an increase in the ecosystem's resilience), we follow Baumgärtner (2007: 103-104). One standard method of how to value the riskiness of an income lottery to a decision maker in monetary terms is to calculate the risk premium $R P$ of the lottery, which is defined by (e.g. Kreps 1990, Varian 1992: 181) ${ }^{7}$

$$
u\left(\mathcal{E}_{R}[y]-R P\right)=\mathcal{E}_{R}[u(y)] .
$$

In words, the risk premium $R P$ is the amount of money that leaves a decision maker equally well-off, in terms of utility, between the two situations of (i) receiving for sure the expected pay-off from the income lottery $R, \mathcal{E}_{R}[y]$, minus the risk premium $R P$, and (ii) playing the risky income lottery $R$ with random pay-off $y .{ }^{8}$ In the model employed here,

\footnotetext{
${ }^{7}$ By Equation (7), $\mathcal{E}_{R}[y]-R P$ is the certainty equivalent of lottery $R$, as it yields exactly the same expected utility as playing the risky lottery, $\mathcal{E}_{R}[u(y)]$.

${ }^{8}$ The risk premium is, thus, the maximum amount of money that a decision maker would be willing
} 
the risk premium as defined by Equation (7) uniquely exists because, by assumption (cf. Section 2), $y \in Y$ with $Y$ as an interval of $\mathbb{R}$, and $u$ is continuous and strictly increasing (Kreps 1990: 84). In general, if the Bernoulli utility function $u$ characterizes a risk averse decision maker, i.e. if $\rho>0$ in Equation (6), the risk premium $R P$ is strictly positive.

The economic insurance value of resilience can now be defined based on the risk premium of the income lottery $R$ as follows.

\section{Definition 2}

The insurance value $V$ of resilience is given by the change of the risk premium $R P$ of the income lottery $R$ due to a marginal change in the level of resilience $R$ :

$$
I V(R):=-\frac{d R P(R)}{d R}
$$

Thus, the economic insurance value of ecosystem resilience is the marginal value of its function to reduce the risk premium of the ecosystem user's income risk from using ecosystem services under uncertainty. Being a marginal value, it depends on the existing level of resilience $R$. The minus sign in the defining Equation (8) serves to express a reduction of the risk premium as a positive value.

As it is apparent already from Definition 2 (and as it will become more explicit in the following section), the economic insurance value of ecosystem resilience has, in general, an objective and a subjective dimension. The objective dimension is captured by the ecosystem's sensitivity of the flip probability $p(R)$ to changes in the level of resilience, $\sigma$; the subjective dimension is captured by the ecosystem user's degree of risk aversion, $\rho$. If the flip probability would not vary with the level of resilience (i.e. $p^{\prime}(R) \equiv 0$ ), or if the ecosystem user was risk-neutral (i.e. $\rho=0$ ), the risk premium $R P$ of income lottery $R$ would not vary with $R$, thus yielding a vanishing insurance value of resilience.

The insurance value of resilience is only a fraction of resilience's total economic value, namely the value of its function to reduce the risk premium of the ecosystem user's income risk from using ecosystem services under uncertainty. Beyond its insurance value, resilience also has economic value in its function to increase the ecosystem user's

to pay for getting the expected pay-off from the income lottery, $\mathcal{E}[y]$, for sure instead of playing the risky income lottery with random pay-off $y$. 
expected income from ecosystem services. In order to characterize the insurance value of resilience as a fraction of its total economic value, we adopt the following general and widely accepted definition of total economic value under uncertainty (e.g. Freeman 2003: Chap. 8).

\section{Definition 3}

The total economic value $T E V$ of resilience is given by the maximum willingness to pay $W T P$ per unit for a marginal increase of $\Delta R$ in the level of resilience $R$ :

$$
T E V(R):=\lim _{\Delta R \rightarrow 0} \frac{W T P(\Delta R)}{\Delta R}
$$

where WTP is defined through

$$
\mathcal{E}_{R}[u(y)]=\mathcal{E}_{R+\Delta R}[u(y-W T P(\Delta R))] .
$$

In words, we measure the total economic value of a change $\Delta R$ in resilience as the maximum willingness to pay $(W T P)$ for that change, more exactly as the WTP per marginal unit of resilience. The maximum willingness to pay for the increase $\Delta R$ in resilience is the amount of money that leaves an individual indifferent, in terms of expected utility, between the two situations of (i) resting in the original position with resilience $R$ and (ii) paying the amount WTP and getting into a situation with resilience $R+\Delta R .^{9}$ As value is typically expressed as a per-unit quantity characterizing a marginal change, we divide $W T P$ by $\Delta R$ and let $\Delta R \rightarrow 0$ to obtain the marginal value of resilience. Being a marginal value, it depends on the existing level of resilience $R$.

${ }^{9}$ In the language of welfare measurement, WTP is the Hicksian compensating surplus for a finite change of $\Delta R$ in the level of resilience (Hicks 1943, Freeman 2003: Chap. 3). Alternatively, one could also use the Hicksian equivalent surplus to measure the monetary value of the welfare change associated with a finite change of $\Delta R$ in the level of resilience, that is, the minimum amount of monetary compensation to the individual ("willingness to accept", $W T A$ ) that leaves the individual indifferent between the two situations of (i) resting in the original position with resilience $R$ and receiving a monetary payment of $W T A$ and (ii) getting into a situation with resilience $R+\Delta R$. In general, $W T P$ and $W T A$ will differ for finite changes of $\Delta R$. However, for the marginal changes studied here, i.e. for $\Delta R \rightarrow 0, W T P$ and $W T A$ coincide, so that the value of $T E V(R)$ does not depend upon whether WTP or WTA is used in the defining Equation (9). 
In the simple model studied here, with no other constraints or alternative options for action in place, the total economic value of resilience as defined by Definition 3, evaluated at the socially optimal level of resilience, is exactly equivalent to its shadow price (as measured e.g. by Mäler et al. 2007, Walker et al. 2007).

\section{Results}

Using the concepts defined in Section 3, we can make statements about the model described in Section 2, and, thus, about the economic insurance value of ecosystem resilience. To start with, we discuss the risk premium associated with different levels of resilience.

\section{Lemma 1}

The risk premium $R P(R)$ of the income lottery $R$ is given by

$$
R P(R)=-p(R) \Delta y+\frac{1}{\rho} \ln \left[1+p(R)\left(e^{\rho \Delta y}-1\right)\right]
$$

which has the following properties:

(i)

$$
R P(0)=R P(1)=0 \quad \text { and } \quad R P(R)>0 \text { for all } R \in(0,1) .
$$

(ii) For all $R \in(0,1)^{10}$

$$
\begin{aligned}
& R P^{\prime}(R)\left\{\begin{array}{l}
\geq \\
\overline{<}
\end{array}\right\} 0 \quad \text { for } \quad R\left\{\begin{array}{l}
\sum \\
\equiv
\end{array}\right\} \tilde{R}, \\
& \text { where } \quad \tilde{R}:=p^{-1}\left(\frac{1}{\rho \Delta y}-\frac{1}{e^{\rho \Delta y}-1}\right), \\
& \text { so that } \underline{R}<\tilde{R}<1 \text { and } \frac{d \tilde{R}}{d \rho}, \frac{d \tilde{R}}{d \Delta y}>0, \frac{d \tilde{R}}{d \sigma}<0
\end{aligned}
$$

(iii) There exists $\bar{\sigma}$ with $0<\bar{\sigma} \leq 1$ and

$$
\frac{d \bar{\sigma}}{d(\rho \Delta y)}>0, \quad \lim _{\rho \Delta y \rightarrow+\infty} \bar{\sigma}=1, \quad \lim _{\rho \Delta y \rightarrow 0} \bar{\sigma}=0
$$

\footnotetext{
${ }^{10}$ For $\sigma=0$, the statement about the sign of $R P^{\prime}(R)$ holds also for $R=0$ and $R=1$. Yet, for $\sigma<0$, one has $R P^{\prime}(0)=0$; for $\sigma \rightarrow 1$, one has $R P^{\prime}(1) \rightarrow 0$.
} 
so that

$$
R P^{\prime \prime}(R)<0 \begin{cases}\text { for } R>\tilde{\tilde{R}} & \text { if } \quad \sigma<0 \\ \text { for all } R \in(0,1) & \text { if and only if } 0 \leq \sigma \leq \bar{\sigma} \\ \text { for } R<\tilde{\tilde{R}} & \text { if } \quad \sigma>\bar{\sigma}\end{cases}
$$

where $\tilde{\tilde{R}}$ is defined through $R P^{\prime \prime}(\tilde{\tilde{R}})=0$ for $\sigma<0$, and through $\tilde{\tilde{R}}=\min \left\{R \mid R P^{\prime \prime}(R)=\right.$ 0 f for $\sigma>\bar{\sigma}$, so that $\tilde{\tilde{R}} \gtrless \tilde{R}$ for $\sigma \gtrless 0$.

(iv) For all $R \in(0,1)$

$$
\begin{aligned}
& \frac{d R P(R)}{d \rho}>0 \quad \text { and } \quad \lim _{\rho \rightarrow 0} R P(R)=0, \\
& \frac{d R P(R)}{d \Delta y}>0 \quad \text { and } \quad \lim _{\Delta y \rightarrow 0} R P(R)=0 \\
& \frac{d R P(R)}{d \sigma}\left\{\begin{array}{c}
\geq \\
\overline{<}
\end{array}\right\} 0 \text { for } \quad R\left\{\begin{array}{c}
\leq \\
\overline{>}
\end{array}\right\} \tilde{R}, \\
& \text { and } \lim _{\sigma \rightarrow 1} R P(R)=\lim _{\sigma \rightarrow-\infty} R P(R)=0 \text {. }
\end{aligned}
$$

Proof. See Appendix A.1.

Result (12) states that the risk premium of income lottery $R$ is strictly positive at all levels of resilience in between 0 and the maximum level of 1 , and is zero at the extreme levels of 0 and 1 . That is, income is risky at all levels of resilience in between 0 and 1; and only at the extreme levels of 0 and 1 does the income risk vanish, as in the case $R=0$ the system will flip into the low-productivity domain with income $y_{L}$ for certain, and at $R=1$ the system will remain in the high-productivity domain with income $y_{L}$ for certain.

As a consequence of Result (12), the risk premium varies with the level of resilience in a non-monotonic way (Figures 1 and 2, orange line). Result (13) states that there uniquely exists a level $\tilde{R}$ of the domain's resilience at which the risk premium is maximal, that is, the income lottery is most risky $(\tilde{R}=0.647$ in Figure $1, \tilde{R}=0.794$ in Figure 2 left, $\tilde{R}=0.004$ in Figure 2 right). For $R>\tilde{R}$ a marginal increase in resilience reduces the 
risk premium, and for $R<\tilde{R}$ a marginal increase in resilience raises the risk premium. This maximum-income-risk level of resilience, $\tilde{R}$ (Equation 14), is strictly in between $\underline{R}$ and 1 , where $\underline{R}>0$ denotes the level of resilience at which the probability of a system flip exactly equals the probability of the system not flipping (Result 15a). ${ }^{11}$ So, the maximum-income-risk level of resilience $\tilde{R}$ is always strictly larger than the level of resilience $\underline{R}$, at which the future state of nature is maximally uncertain. Also, the range $(0, \tilde{R}]$ of low levels of resilience, for which the risk premium is strictly increasing with resilience, is non-empty.

Furthermore, the maximum-income-risk level of resilience $\tilde{R}$ increases with the degree of risk aversion $\rho$ and the potential income loss $\Delta y$, it decreases with the ecosystem's elasticity $\sigma$ (Result 15b).

The statement about the second derivative of the risk premium (Result 17) is rather technical, and will be needed for the proof of an important property of the insurance value in Proposition 1 below. Essentially, it states that there exists a domain of (positive) values of ecosystem elasticity, $0 \leq \sigma \leq \bar{\sigma}$, including the preeminent case of $\sigma=0$, for which the risk premium is strictly concave over the entire range of resilience (Figure 1, orange line). This domain of ecosystem elasticities is bounded from below by zero, and from above by some maximal value $\bar{\sigma}$, which has the properties stated in Result (16): it increases with the risk-aversion-weighted potential income loss, $\rho \Delta y$, and for $\rho \Delta y$ going to infinity (zero) approaches the maximal ecosystem elasticity of one (zero).

The more risk-averse the ecosystem user is, the larger the perceived riskiness of the income lottery $R$ and the larger the associated risk premium (Result 18). For a riskneutral individual, on the other hand, the risk premium would be 0 for all $R$. Similarly, for the potential income loss $\Delta y$ (Result 19): the risk premium raises with an increasing potential income loss $\Delta y$. For equal income levels in both stability domains, which means no income loss in case of a system flip $(\Delta y=0)$, the risk premium would be zero over the whole range of $R$.

Result (20) states that the risk premium increases (decreases) with the ecosystem's

\footnotetext{
${ }^{11}$ Note that $\underline{R}$, which is defined through $p(\underline{R})=1 / 2$, will be greater than (equal to, smaller than) $1 / 2$ for $\sigma<0(=0,>0)$.
} 
elasticity for levels of resilience below (above) the maximum-income-risk level of resilience, $\tilde{R}$. That is, in the range of resilience where the riskiness of income increases (decreases) with resilience, i.e. for $R<(>) \tilde{R}$ (cf. Result 13), an increase in ecosystem elasticity increases (decreases) the riskiness of income. This can be seen from comparing the orange lines in Figures 2 (left), 1 and 2 (right), as $\sigma$ increases in this order. Ecosystem elasticity thus has the very same ambivalent role as ecosystem resilience for the riskiness of income. Result (21) states that the risk premium vanishes as the ecosystem's elasticity approaches either its maximum or its minimum value. The reason is that in either limiting case, according to model (4), the flip probability $p(R)$ does not depend on the level of resilience any more, except for the extreme levels of $R=0$ (for $\sigma \rightarrow 1$ ) or $R=1$ (for $\sigma \rightarrow-\infty$ ) where it jumps from one to zero or from zero to one, respectively. As a result, the risk premium is non-vanishing only at $R=0$ (for $\sigma \rightarrow 1$ ) or $R=1$ (for $\sigma \rightarrow-\infty$ ), but vanishes for all other levels of resilience. ${ }^{12}$

Having explored the effect of the ecosystem user's risk preferences and ecosystem properties on the risk premium of income lottery $R$, we can now discuss the insurance value of resilience as introduced in Definition 2.

\section{Proposition 1}

The insurance value of resilience, $I V(R)$, is given by

$$
I V(R)=p^{\prime}(R)\left\{\Delta y-\frac{1}{\rho} \frac{e^{\rho \Delta y}-1}{1+p(R)\left(e^{\rho \Delta y}-1\right)}\right\}
$$

which has the following properties:

(i) For all $R \in(0,1)^{13}$

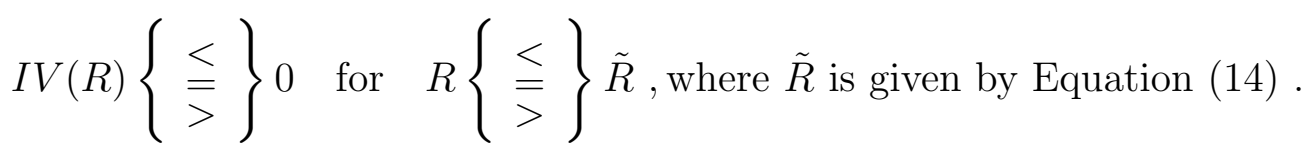

\footnotetext{
${ }^{12}$ Note that an overall vanshing risk premium, except for either $R=0$ (for $\sigma \rightarrow 1$ ) or $R=1$ (for $\sigma \rightarrow-\infty$ ) is compatible with Result (20)'s statement that the risk premium increases with $\sigma$ for $R<\tilde{R}$, because $\tilde{R}$ decreases with $\sigma$ (Result 15 ).

${ }^{13}$ For $\sigma=0$, the statement about the sign of $I V(R)$ holds also for $R=0$ and $R=1$. Yet, for $\sigma<0$, one has $I V(0)=0$; for $\sigma \rightarrow 1$, one has $I V(1) \rightarrow 0$.
} 
(ii) The insurance value is globally increasing with resilience,

$$
I V(0)<I V(1)
$$

in particular, it is strictly monotonically increasing depending on ecosystem elasticity:

$$
I V^{\prime}(R)>0 \begin{cases}\text { for } R>\tilde{\tilde{R}} & \text { if } \sigma<0 \\ \text { for all } R \in(0,1) & \text { if and only if } 0 \leq \sigma \leq \bar{\sigma} \\ \text { for } R<\tilde{\tilde{R}} & \text { if } \quad \sigma>\bar{\sigma}\end{cases}
$$

where $\bar{\sigma}$ and $\tilde{\tilde{R}}$ are as defined in Lemma $1($ iii).

(iii) For all $R \in(0,1)$

$$
\begin{aligned}
& \frac{d I V(R)}{d \rho}\left\{\begin{array}{c}
\leq \\
\equiv
\end{array}\right\} 0 \quad \text { for } \quad R\left\{\begin{array}{c}
\leq \\
\overline{>}
\end{array}\right\} \tilde{R} \quad \text { and } \quad \lim _{\rho \rightarrow 0} I V(R)=0 \\
& \frac{d I V(R)}{d \Delta y}\left\{\begin{array}{c}
\vdots \\
>
\end{array}\right\} 0 \text { for } R\left\{\begin{array}{c}
\vdots \\
\equiv
\end{array}\right\} \tilde{R} \quad \text { and } \quad \lim _{\Delta y \rightarrow 0} I V(R)=0 \\
& \frac{d I V(R)}{d \sigma}\left\{\begin{array}{c}
< \\
= \\
> \\
= \\
<
\end{array}\right\} 0 \quad \text { for } \quad\left\{\begin{array}{c}
R<' R \\
R=' R \\
' R<R<R^{\prime} \\
R=R^{\prime} \\
R>R^{\prime}
\end{array}\right. \\
& \text { and } \lim _{\sigma \rightarrow 1} I V(R)=\lim _{\sigma \rightarrow-\infty} I V(R)=0 \text {, }
\end{aligned}
$$

where $\tilde{R}$ is as defined in Lemma 1 (iii) and ' $R<\tilde{R}<R^{\prime}$.

Proof. See Appendix A.2.

Result (23) states that the insurance value of resilience may be negative or positive, depending on the level of resilience $R$. If resilience is below the maximum-income-risk level $\tilde{R}$, an increases in resilience raises the risk premium (Result 13) and therefore, as the insurance value is defined as the reduction in the risk premium (Definition 2), resilience has a negative insurance value for all $R<\tilde{R}$. Only if $R>\tilde{R}$, an increase in resilience reduces the risk premium and the insurance value is positive (Figures 1 and 2 , green line). 


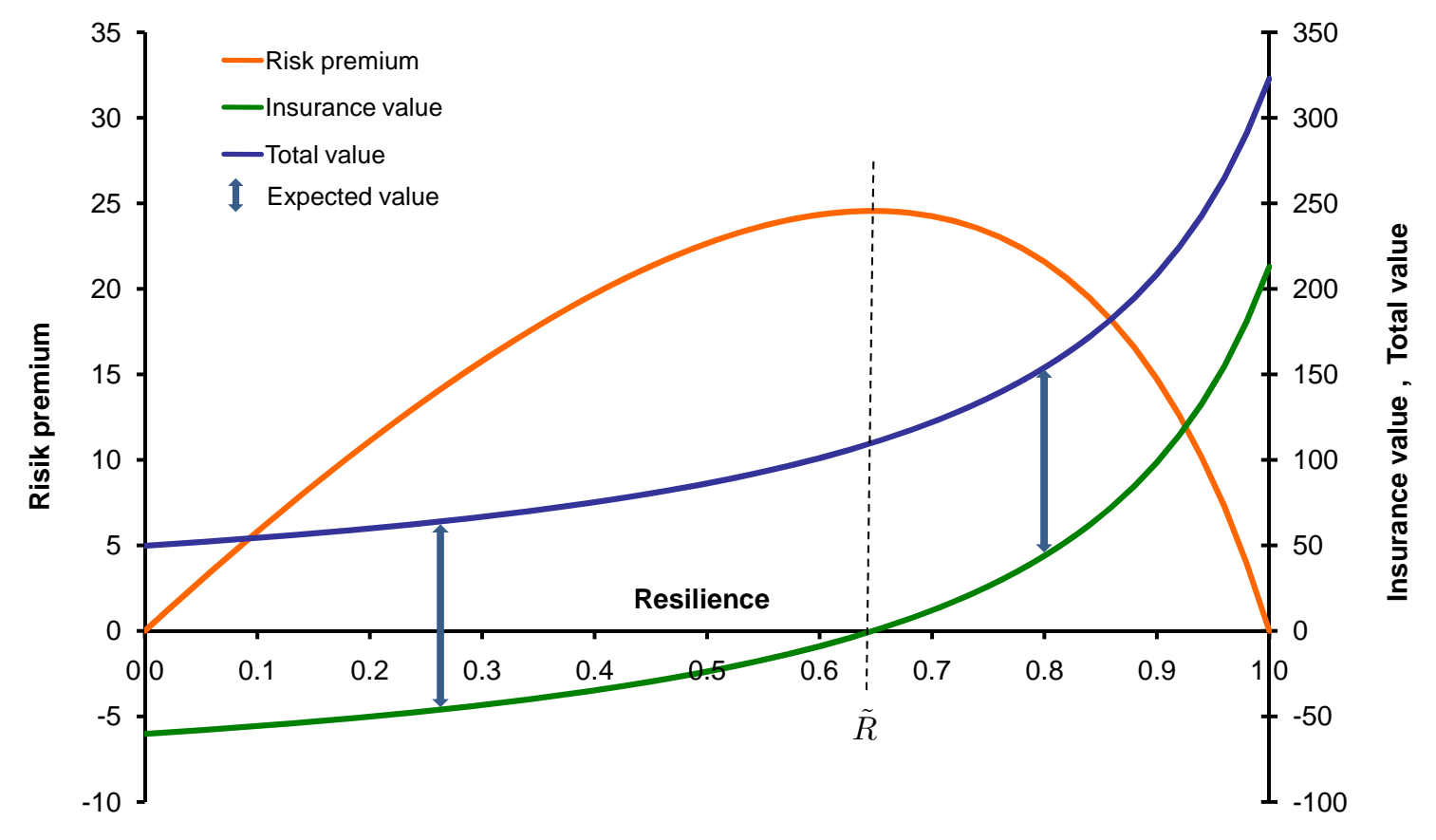

Figure 1: Risk premium (orange curve), insurance value (green curve), expected value (vertical distance between green and blue curves) and total value (blue curve) as a function of resilience for the case of intermediate ecosystem elasticity $0 \leq \sigma \leq \bar{\sigma}$. The dashed line marks the maximum-income-risk level of resilience $R=\tilde{R}$. (Parameter values: $\sigma=0, \Delta y=110, \rho=0.017)$

Result (24) states that the insurance value of ecosystem resilience globally increases with the level of resilience: it is strictly higher for the maximum level of resilience than for zero resilience. Result (25) states that for a domain of (positive) values of ecosystem elasticity, $0 \leq \sigma \leq \bar{\sigma}$ (including the preeminent case of $\sigma=0$ ), the insurance value of ecosystem resilience increases even strictly monotonically with the level of resilience (Figure 1, green line). Only as ecosystem elasticity $\sigma$ turns negative or exceeds the threshold value $\bar{\sigma}$, it may happen that the insurance value locally decreases. ${ }^{14}$ For

\footnotetext{
${ }^{14} \mathrm{~A}$ parameter value of $\sigma<0$ in Function (4) implies a relationship between $p$ and $R$ such that the first marginal units of resilience starting from $R=0$ do not have any significant impact on the reduction of the flip probability $p$. Only increases in resilience close to the maximum level of $R=1$ do
} 

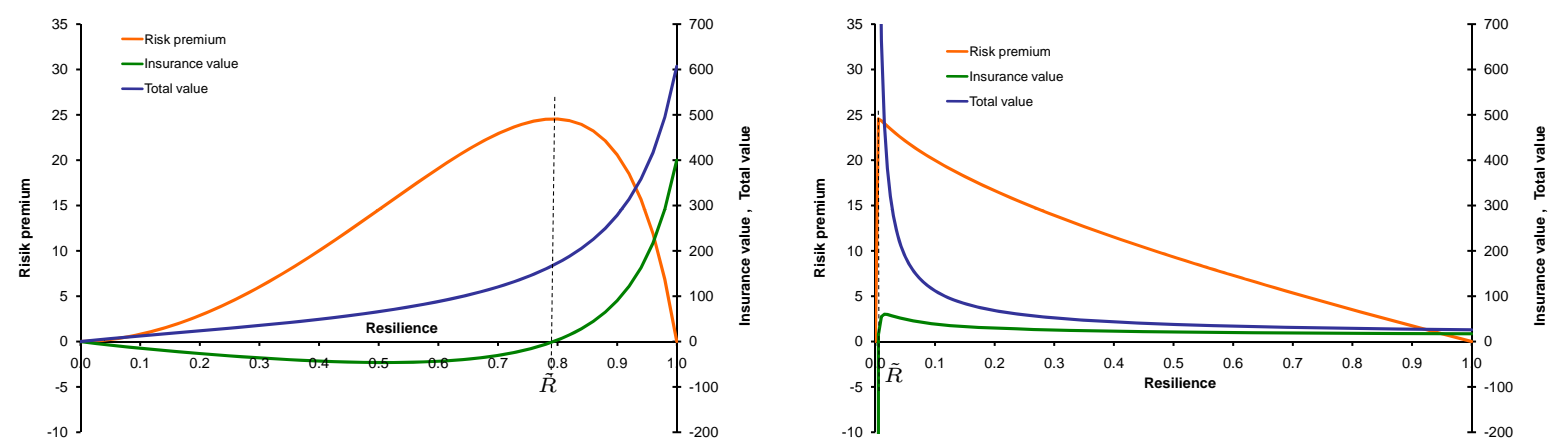

Figure 2: Risk premium (orange curve), insurance value (green curve), expected value (vertical distance between green and blue curves) and total value (blue curve) as a function of resilience for the two extreme cases of negative ecosystem elasticity $(\sigma<0$, left) and very large positive ecosystem elasticity $(\sigma>\bar{\sigma}$, right). The dashed line marks the maximum-income-risk level of resilience $R=\tilde{R}$. (Parameter values, left: $\sigma=-0.88$; right: $\sigma=0.92$; both: $\Delta y=110, \rho=0.017)$

negative ecosystem elasticity, $\sigma<0$, it may be that the (negative) insurance value locally decreases at levels of resilience smaller than $\tilde{\tilde{R}}$ (Figure 2 left, green line); and for very large positive ecosystem elasticity, $\sigma>\bar{\sigma}$, it may be that the (positive) insurance value locally decreases at levels of resilience greater than $\tilde{\tilde{R}}$ (Figure 2 right, green line).

In economic terms, an increasing insurance value means that the higher the level of resilience, the more valuable - as an insurance - is a marginal increase in resilience. This is unusual and in contrast to normal economic goods, the marginal value of which decreases with their amount: normally, the more abundant a good, the less valuable the next marginal unit. Technically, the increasing marginal value of resilience comes about significantly lower the flip probability $p$. For such ecosystems, the insurance value of resilience decreases for small levels of resilience and increases for high levels of resilience close to $R=1$ (Figure 2 left, green line). Conversely, a parameter value of $\sigma$ close to its maximum value of $R=1$ means that the first marginal unit of resilience has a huge impact on the reduction of the flip probability $p$, whereas all later units of resilience only have a negligible effect. Under such circumstances, the insurance value of resilience steeply increases in the vicinity of $R=0$ from a negative value to its maximum (positive) value and then decreases with $R$ (Figure 2 right, green line). 
as the objective function, expected utility (5), when expressed as a function of the level of resilience, is non-concave in $R$.

Result (26) states how the ecosystem user's degree of risk-aversion affects the insurance value. If the ecosystem user was risk neutral $(\rho=0)$, the insurance value would vanish for all levels of resilience $R$. With increasing risk-aversion, the insurance value increases for high levels of $R>\tilde{R}$, where it is positive, and decreases for low levels of $R<\tilde{R}$, where it is negative. Thus, the more risk-averse the ecosystem user is, the steeper the curve for $I V$ (Figure 1, green line). The same goes for the potential income loss $\Delta y$ (Result 27). For equal income levels in both stability domains, which means no income loss in case of a system flip $(\Delta y=0)$, the insurance value would vanish for all levels of resilience $R$. With increasing potential income loss $\Delta y$, the $I V$-curve gets steeper, as the insurance value decreases for $R<\tilde{R}$ and raises for $R>\tilde{R}$.

Also, $\tilde{R}$ shifts to the right with both increasing risk-aversion $\rho$ and increasing potential income loss $\Delta y$. For very high values of $\rho$ or $\Delta y$ the $I V$-curve appears to be sharply bended around $\tilde{R}$, since the insurance value raises faster with $\rho$ or $\Delta y$ in the range of $R>\tilde{R}$ than it decreases in the range of $R<\tilde{R}$.

Result (28) states that the insurance value decreases with increasing ecosystem elasticity for low and high levels of resilience, $R<^{\prime} R<\tilde{R}$ and $R>R^{\prime}>\tilde{R}$, and increases with increasing ecosystem elasticity in between, ' $R<R<R^{\prime}$. This can be seen from comparing the green lines in Figures 2 (left), 1 and 2 (right), as $\sigma$ increases in this order. Result (29) states that the insurance value vanishes as the ecosystem's elasticity approaches either its maximum or its minimum value, which becomes plausible from the underlying property of the risk premium (Result 21). This can also be seen from comparing the green lines in Figures 2 (left and right) and 1.

Having discussed the effect of the ecosystem user's risk preferences and ecosystem properties on the insurance value of resilience, we now turn to discussing how the insurance value of ecosystem resilience relates to its total economic value (Definition 3).

\section{Proposition 2}


The total economic value of resilience, $T E V(R)$, is given by

$$
T E V(R)=-p^{\prime}(R) \frac{1}{\rho} \frac{e^{\rho \Delta y}-1}{1+p(R)\left(e^{\rho \Delta y}-1\right)},
$$

which has the following properties:

(i)

$$
T E V(R) \equiv-p^{\prime}(R) \Delta y+I V(R)
$$

(ii)

$$
T E V(R) \geq 0 \text { for all } R \text {. }
$$

Proof. See Appendix A.3.

From Equation (31) it becomes obvious that the total economic value of resilience is the sum of two components: the expected increase in income due to a marginal increase in resilience, $-p^{\prime}(R) \Delta y$, which is always positive: ${ }^{15}$ and the insurance value of increased resilience, which may be negative or positive (cf. Proposition 1). This reflects the fact that an increase in ecosystem resilience has two effects on the ecosystem user's income: (i) it raises the expected income; (ii) it may raise or lower the riskiness of income, i.e. deviations from expected income. Thus, the total value of resilience is more than its insurance value, or, put the other way round, the insurance value is a value component over and above the expected value of resilience.

Figures 1 and 2 show the total economic value as a function of resilience (blue line). In the figures, the expected value of resilience, $-p^{\prime}(R) \Delta y$, is just the vertical difference between the curves for $I V$ (green) and $T E V$ (blue). Whereas the insurance value $I V(R)$ of resilience may be positive or negative, depending on the level of resilience $R$, the expected value of resilience, $-p^{\prime}(R) \Delta y$, is positive at all levels of resilience $R .{ }^{16}$ As a consequence, for $R<\tilde{R}$ where the insurance value is negative, the total economic value of resilience is smaller than its expected value. Yet, at all levels of resilience the

\footnotetext{
${ }^{15}$ By Assumption (2), $p^{\prime}(R)<0$ for all $R \in(0,1)$.

${ }^{16}$ Note that for $\sigma=0$, one has $p^{\prime}(R)=-1=$ const., so that the expected value of resilience does not depend on the level of resilience. That is, the vertical difference between the curves for $I V$ (green) and TEV (blue) in Figure 1 is constant.
} 
total value is positive (Result 32). That means, even if the insurance value should be negative, the mean-increasing value of resilience is large enough to offset this negative effect on the total value.

\section{Discussion and conclusion}

In this paper we have provided a conceptual clarification of the economic insurance value of ecosystem resilience. We have adopted a general and widely accepted definition of insurance as mitigation of the influence of uncertainty on a person's well-being (McCall 1987), and of insurance value as a reduction in the risk premium of the person's income risk lottery (Baumgärtner 2007). That way, we have clearly distinguished the insurance value of ecosystem resilience, which is due to its function to reduce the riskiness of income ("risk mitigation"), from other components of its total economic value, which are due to resilience's function to raise the expected income from ecosystem services.

Our analysis has yielded several interesting and important results. First, the insurance value of resilience is negative for low levels of resilience and positive for high levels of resilience. That is, ecosystem resilience actually functions as an economic insurance, i.e. it reduces the riskiness of income from ecosystem services, only at sufficiently high levels of resilience; it does not function as an economic insurance but - just on the contrary - increases the riskiness of income at low levels of resilience.

Second, the (marginal) insurance value as well as the (marginal) total value of resilience increase globally with the level of resilience - for some ecosystem types (namely those with moderately positive elasticity) even monotonically: the higher the level of resilience, the more valuable is another unit of resilience. This is in contrast to normal economic goods, the (marginal) value of which decreases with their quantity. As unusual as this increasing-returns property may be for normal economic goods, it is not implausible and also known from other goods which are of systemic importance and thus give rise to a non-concavity in the social objective function, such as e.g. information (Radner and Stiglitz 1984) or biodiversity conservation (Hunter 2009). The management consequences for such non-convex ecological-economic systems are discussed e.g. by Dasgupta 
and Mäler (2003).

Third, the insurance value of resilience is one additive component of its total economic value. The other component is the rise in expected income due to a higher level of resilience. So, the insurance value of resilience, which is due to its risk-mitigation function, is a value component over and above the change in the expected value of the income lottery. While the former may be positive or negative, the latter is always positive, and the total economic value of resilience is always positive. One reason for distinguishing between the two value components of ecosystem resilience, and for studying the insurance value separately, might be that in an encompassing management-and-decision context the different functions of resilience may have different substitutes. For example, in many rural areas of developing countries there is no substitute for agro-ecosystem resilience in enhancing the mean level of farming income, but there is now more and more financial insurance available that serves as a substitute for resilience's function to mitigate income risks (Baumgärtner and Quaas 2008, Quaas and Baumgärtner 2008).

While we have made one specific assumption about risk preferences, i.e. constant absolute risk aversion, actually all of our results qualitatively hold more generally for all risk preferences satisfying the von-Neumann-Morgenstern axioms. These axioms, including continuity and context-independence, appear plausible for standard small-risk situations. But one may doubt that they adequately describe people's risk preferences when it comes to catastrophic (i.e. discontinuous) risk that irreversibly threatens the subsistence level of income, as it is the case for many threats to the resilience of lifesupporting ecosystems. For such risks, it may be interesting to study how resilience provides insurance under, e.g., safety-first preferences (Roy 1952, Telser 1955, Kataoka 1963).

One general lesson from our analysis for further discussions of resilience as an insurance is that the concept of insurance fundamentally refers to both the objective characteristics of risk in terms of different possible states of nature and people's subjective risk preferences over these states. In particular, explicit reference to people's risk preferences is needed to meaningfully discuss insurance, to specify the economic insurance value of resilience, and to meaningfully distinguish the insurance value from 
other components of the total economic value of ecosystem resilience.

\section{Acknowledgments}

We are grateful to Martin Quaas for helpful discussion and comments.

\section{Appendix}

Throughout the appendix, we denote the risk-aversion-weighted income loss by $\lambda \equiv \rho \Delta y$.

\section{A.1 Proof of Lemma 1}

Explicating the general definition of the risk premium (Equation 7) by the CARA-utility function (6) yields

$$
-e^{-\rho\left[(1-p(R)) y_{H}+p(R) y_{L}-R P(R)\right]}=-(1-p(R)) e^{-\rho y_{H}}-p(R) e^{-\rho y_{L}},
$$

which can be rearranged into

$$
e^{\rho R P(R)}=\frac{(1-p(R)) e^{-\rho y_{H}}+p(R) e^{-\rho y_{L}}}{e^{-\rho\left[(1-p(R)) y_{H}+p(R) y_{L}\right]}} .
$$

Using $\Delta y=y_{H}-y_{L},($ A.34) can be solved for $R P(R)$, which leads to Result (11).

ad (i). Inserting $p(0)=1$ or $p(1)=0$ into (11) immediately yields $R P=0$ (Result 12a). Strict positivity of $R P(R)$ for all $R \in(0,1)$ (Result $12 \mathrm{~b}$ ) can be demonstrated as follows. Note that

$$
1-p(R)>e^{p(R) \lambda}-p(R) e^{\lambda}
$$

because the right hand side of this inequality approaches $1-p(R)$ as $\lambda \rightarrow 0$ and strictly monotonically decreases with $\lambda$,

$$
\frac{d}{d \lambda}\left[e^{p(R) \lambda}-p(R) e^{\lambda}\right]=p(R)\left(e^{p(R) \lambda}-e^{\lambda}\right)<0
$$


since $\lambda>0$ and $R \in(0,1)$, i.e. $0<p(R)<1$. Inequality (A.35) can be rearranged

$$
\begin{aligned}
1-p(R) & >e^{p(R) \lambda}-p(R) e^{\lambda} \\
1+p(R)\left(e^{\lambda}-1\right) & >e^{p(R) \lambda} \\
\ln \left[1+p(R)\left(e^{\lambda}-1\right)\right] & >p(R) \lambda \\
-p(R) \lambda+\ln \left[1+p(R)\left(e^{\lambda}-1\right)\right] & >0,
\end{aligned}
$$

which yields, after dividing by $\rho>0$, Result (12)b.

ad (ii). Differentiating Result (11) with respect to $R$ yields

$$
R P^{\prime}(R)=-\frac{p^{\prime}(R)}{\rho}\left\{\lambda-\frac{e^{\lambda}-1}{1+p(R)\left(e^{\lambda}-1\right)}\right\} .
$$

By Assumption (2), $p^{\prime}(R)$ is strictly negative for all $R \in(0,1)$. Hence, the sign of $R P^{\prime}(R)$ is determined by the sign of the term in braces. For $R \rightarrow 0$, using $e^{x}>1+x$ for all $x \neq 0$, one has

$$
\begin{aligned}
\lim _{R \rightarrow 0} \lambda-\frac{e^{\lambda}-1}{1+p(R)\left(e^{\lambda}-1\right)} & =\lambda-\frac{e^{\lambda}-1}{1+\left(e^{\lambda}-1\right)}=\lambda-1+e^{-\lambda} \\
& >\lambda-1+1-\lambda=0
\end{aligned}
$$

For $R \rightarrow 1$, and again using $e^{x}>1+x$ for all $x \neq 0$, one has

$$
\begin{aligned}
\lim _{R \rightarrow 1} \lambda-\frac{e^{\lambda}-1}{1+p(R)\left(e^{\lambda}-1\right)} & =\lambda-\frac{e^{\lambda}-1}{1+0}=\lambda-e^{\lambda}+1 \\
& <\lambda-1-\lambda+1=0
\end{aligned}
$$

And $R P^{\prime}(R)=0$ for

$$
\lambda-\frac{e^{\lambda}-1}{1+p(\tilde{R})\left(e^{\lambda}-1\right)}=0 .
$$

This can be uniquely solved for $R=\tilde{R}$ where $\tilde{R}$ is defined through

$$
p(\tilde{R})=\frac{1}{\lambda}-\frac{1}{e^{\lambda}-1},
$$

which is equivalent to Result (14), since $p^{\prime}(R) \neq 0$ for all $R \in(0,1)$. Pulling all this information together, from $R P^{\prime}(0)>0$ (A.41), $R P^{\prime}(1)<0$ (A.42), and $R P^{\prime}(R)=0$ if and only if $R=\tilde{R}$ (A.44), it follows that Result (13) holds. 
In order to study the properties of $\tilde{R}$ (Equation 14) introduce

$$
F(\lambda)=\frac{1}{\lambda}-\frac{1}{e^{\lambda}-1}
$$

so that (A.44) and (14) can be rewritten as

$$
p(\tilde{R}) \equiv F(\lambda) \quad \text { and } \quad \tilde{R} \equiv p^{-1}(F(\lambda))
$$

Note that

$$
\lim _{\lambda \rightarrow 0} F(\lambda)=\lim _{\lambda \rightarrow 0} \frac{e^{\lambda}-1-\lambda}{\lambda\left(e^{\lambda}-1\right)}=\lim _{\lambda \rightarrow 0} \frac{e^{\lambda}-1}{(1+\lambda) e^{\lambda}-1}=\lim _{\lambda \rightarrow 0} \frac{1}{2+\lambda}=\frac{1}{2}
$$

(apply l'Hôpital's rule twice)

$$
\begin{aligned}
\lim _{\lambda \rightarrow+\infty} F(\lambda)= & \lim _{\lambda \rightarrow+\infty} \frac{1}{\lambda}-\lim _{\lambda \rightarrow+\infty} \frac{1}{e^{\lambda}-1}=0 \\
F^{\prime}(\lambda)= & -\frac{1}{\lambda^{2}}+\frac{e^{\lambda}}{\left(e^{\lambda}-1\right)^{2}}=\frac{1}{e^{\lambda}+e^{-\lambda}-2}-\frac{1}{\lambda^{2}}<0 \quad \text { for all } \lambda, \\
& \text { (as, through Taylor expansion, } e^{\lambda}=\sum_{n=0}^{\infty} \frac{\lambda^{n}}{n !} \quad \text { and therefore }
\end{aligned}
$$$$
\left.e^{\lambda}+e^{-\lambda}-2=\lambda^{2}+\sum_{n=1}^{\infty} \frac{2 \lambda^{2 n}}{(2 n) !}>\lambda^{2} \text { for all } \lambda\right)
$$$$
F(\lambda)>0 \text { for all } \lambda
$$

(follows immediately from A.47-A.49)

From (A.50) it follows immediately that $p(\tilde{R})=F(\lambda)>0$ for all $\lambda$, which implies, with $p^{\prime}(R)<0$ for all $R$, that $\tilde{R}<1$ for all $\lambda$. On the other hand, from (A.47) and (A.49) one has that $F(\lambda)<1 / 2$ for all $\lambda>0$. Hence, $p(\tilde{R})=F(\lambda)<1 / 2$ for all $\lambda$, which implies, with $p^{\prime}(R)<0$ for all $R \in(0,1)$, that $\tilde{R}>\underline{R}$ for all $\lambda$. This establishes Result (15 $)$.

With (A.46), Assumption $2\left(p^{\prime}(R)<0\right.$ for all $\left.R \in(0,1)\right)$ and Property (A.49), it follows that

$$
\frac{d \tilde{R}}{d \lambda}=\frac{1}{p^{\prime}(\tilde{R})} F^{\prime}(\lambda)>0 .
$$

From that, with $\lambda \equiv \rho \Delta y$ it follows immediately that $d \tilde{R} / d \rho>0$ and $d \tilde{R} / d \Delta y>0$ (Result 15b). Using (4) and (A.46), $\tilde{R}$ can be rewritten as

$$
\tilde{R}=p^{-1}(F(\lambda))=[1-F(\lambda)]^{\frac{1}{1-\sigma}},
$$


from which it it follows that

$$
\frac{d \tilde{R}}{d \sigma}=[1-F(\lambda)]^{\frac{1}{1-\sigma}} \ln [1-F(\lambda)] \frac{1}{(1-\sigma)^{2}}<0,
$$

since $0<F(\lambda)<1 / 2$ (from A.47-A.50) and $\sigma<1$ (by Assumption 4) imply that the first and third factors are strictly positive and the second is strictly negative.

ad (iii). Differentiate (A.40) again with respect to $R$ :

$$
R P^{\prime \prime}(R)=-\frac{1}{\rho}\left\{p^{\prime \prime}(R)\left[\lambda-\frac{e^{\lambda}-1}{1+p(R)\left(e^{\lambda}-1\right)}\right]+\left[p^{\prime}(R) \frac{e^{\lambda}-1}{1+p(R)\left(e^{\lambda}-1\right)}\right]^{2}\right\}
$$

Under Assumption (4) one has

$$
\begin{aligned}
p(R) & =1-R^{1-\sigma} \\
p^{\prime}(R) & =-(1-\sigma) R^{-\sigma} \\
p^{\prime \prime}(R) & =\sigma(1-\sigma) R^{-\sigma-1}
\end{aligned}
$$

Inserting (A.55)-(A.57) into (A.54) yields an explicit equation for $R P^{\prime \prime}(R)$ in the elementary parameters of the model, $\sigma, \rho$ and $\Delta y$. Systematic numerical simulation of this equation for all $-\infty<\sigma<1$ and for various $\rho, \Delta y>0$ yields Results (16) and (17). $a d$ (iv). By definition, the risk premium is zero for a risk-neutral decision-maker $(\rho=0)$, and is known to increase with her degree of risk-aversion $\rho$ (e.g. Gravelle and Rees 2004: 463), which yields Result (18).

Setting $\Delta y=0$ in Expression (11) for $R P(R)$ obviously yields $R P(R) \equiv 0$. That the risk premium increases with $\Delta y$ can be seen from the first derivative of $R P(R)$ with respect to $\Delta y$ :

$$
\begin{aligned}
\frac{d R P(R)}{d \Delta y} & =p(R)\left[\frac{e^{\lambda}}{1+p(R)\left(e^{\lambda}-1\right)}-1\right] \\
& =p(R)\left[\frac{1}{p(R)+(1-p(R)) e^{-\lambda}}-1\right]
\end{aligned}
$$

As $e^{-\lambda}<1$ for $\lambda>0$, and $0<p(R)<1$ for $R \in(0,1)$, the denominator in the fraction is strictly smaller than 1 , so that the term in brackets is strictly positive and the whole expression is strictly positive, which yields Result (19). 
From Result (11) it follows that

$$
\frac{d R P(R)}{d \sigma}=-\frac{1}{\rho}\left\{\lambda-\frac{e^{\lambda}-1}{1+p(R)\left(e^{\lambda}-1\right)}\right\} \frac{d p(R)}{d \sigma} .
$$

From (A.40) it is apparent that

$$
\left\{\lambda-\frac{e^{\lambda}-1}{1+p(R)\left(e^{\lambda}-1\right)}\right\}=-\rho \frac{R P^{\prime}(R)}{p^{\prime}(R)},
$$

so that (A.59) becomes

$$
\frac{d R P(R)}{d \sigma}=\frac{R P^{\prime}(R)}{p^{\prime}(R)} \frac{d p(R)}{d \sigma} .
$$

As $p^{\prime}(R)<0$ for all $R \in(0,1)$, and, with Assumption (4), $d p(R) / d \sigma<0$ for all $R \in$ $(0,1)$, the sign of $d R P(R) / d \sigma$ is determined by the sign of $R P^{\prime}(R)$. With Result (13), Result (20) then follows immediately.

Result (21) follows from Result (11) and noting that model (4) implies

$$
\lim _{\sigma \rightarrow 1} p(R)=0 \quad \text { as well as } \quad \lim _{\sigma \rightarrow-\infty} p(R)=1 \quad \text { for all } R \in(0,1)
$$

\section{A.2 Proof of Proposition 1}

Differentiating $-R P(R)$ with respect to $R$ immediately yields Result (22).

ad (i). Result (23) follows immediately from Definition (8) and Result (13).

ad (ii). Result (24) can be demonstrated by noting that Result (22) implies

$$
I V(0)=p^{\prime}(0) \frac{1}{\rho}\left(\lambda-1+e^{-\lambda}\right) \quad \text { and } \quad I V(1)=p^{\prime}(1) \frac{1}{\rho}\left(\lambda-e^{\lambda}+1\right),
$$

where

$$
\lambda-1+e^{-\lambda}>0 \text { and } \lambda-e^{\lambda}+1<0
$$

since $e^{x}>1+x$ for all $x>0$. Under Assumption (4), one has (A.56), so that

$$
\left\{\begin{array}{l}
p^{\prime}(0)=0 \text { and } p^{\prime}(1)<0 \\
p^{\prime}(0)<0 \text { and } p^{\prime}(1)<0 \\
p^{\prime}(0)<0 \text { and } p^{\prime}(1) \leq \mathrm{C}^{17}
\end{array}\right\} \quad \text { if } \quad\left\{\begin{array}{c}
\sigma<0 \\
\sigma=0 \\
\sigma>0
\end{array}\right\} \text {. }
$$


Combining (A.63)-(A.65), one has

$$
\left\{\begin{array}{l}
I V(0)=0 \text { and } I V(1)>0 \\
I V(0)<0 \text { and } I V(1)>0 \\
I V(0)<0 \text { and } I V(1) \geq 0^{18}
\end{array}\right\} \text { if }\left\{\begin{array}{c}
\sigma<0 \\
\sigma=0 \\
\sigma>0
\end{array}\right\}
$$

which means that, in any case, $I V(0)<I V(1)$, which is Result (24). Result (25) follows immediately from Definition (8) and Result (17).

ad (iii). Results (26), (27), (28) follow from Definition (8), the fact that the function $R P(R)$ is continuous and differentiable, and Results (12), (18), (19), (20). In, addition, systematic numerical simulations of Equation (23), using model (4), for all $-\infty<$ $\sigma<1$ and for various $\rho, \Delta y>0$ have been employed to demonstrate Result (28). Result (29) follows from Definition (8), the fact that the function $R P(R)$ is continuous and differentiable, and Result (21).

\section{A.3 Proof of Proposition 2}

Explicating the general Definition of the ecosystem user's WTP (Equation 10) by the CARA-utility function (6) yields

$$
\begin{aligned}
& -(1-p(R)) e^{-\rho y_{H}}-p(R) e^{-\rho y_{L}} \\
= & -\left[p(R+\Delta R) e^{-\rho\left(y_{L}-W T P(\Delta R)\right)}+(1-p(R+\Delta R)) e^{-\rho\left(y_{H}-W T P(\Delta R)\right)}\right] \\
= & -e^{\rho W T P(\Delta R)}\left[p(R+\Delta R) e^{-\rho y_{L}}+(1-p(R+\Delta R)) e^{-\rho y_{H}}\right] .
\end{aligned}
$$

Rearranging leads to

$$
-e^{\rho W T P(\Delta R)}=\frac{-(1-p(R)) e^{-\rho y_{H}}-p(R) e^{-\rho y_{L}}}{\left[p(R+\Delta R) e^{-\rho y_{L}}+(1-p(R+\Delta R)) e^{-\rho y_{H}}\right]} .
$$

Solving for $W T P(\Delta R)$, using $\Delta y=y_{H}-y_{L}$ and $\lambda \equiv \rho \Delta y$, yields

$$
W T P(\Delta R)=\frac{1}{\rho} \ln \frac{(1-p(R))+p(R) e^{\lambda}}{(1-p(R+\Delta R))+p(R+\Delta R) e^{\lambda}} .
$$

\footnotetext{
${ }^{17} p^{\prime}(1)<0$ for $\sigma<1$, and $p^{\prime}(1) \rightarrow 0$ as $\sigma \rightarrow 1$.

${ }^{18} I V(1)>0$ for $\sigma<1$, and $I V(1) \rightarrow 0$ as $\sigma \rightarrow 1$.
} 
Using (A.71) in Definition 3 and applying l'Hôpital's rule, one has

$$
\begin{aligned}
T E V(R) & =\frac{1}{\rho} \lim _{\Delta R \rightarrow 0} \frac{\ln \frac{(1-p(R))+p(R) e^{\lambda}}{(1-p(R+\Delta R))+p(R+\Delta R) e^{\lambda}}}{\Delta R} \\
& =\frac{1}{\rho} \lim _{\Delta R \rightarrow 0} \frac{(1-p(R+\Delta R))+p(R+\Delta R) e^{\lambda}}{(1-p(R))+p(R) e^{\lambda}} \\
& \times \frac{d}{d \Delta R}\left[\frac{1-p(R)+p(R) e^{\rho \Delta y}}{1-p(R+\Delta R)+p(R+\Delta R) e^{\lambda}}\right] \\
& =\frac{1}{\rho} \lim _{\Delta R \rightarrow 0} \frac{d}{d \Delta R}\left[\frac{1-p(R)+p(R) e^{\lambda}}{1-p(R+\Delta R)+p(R+\Delta R) e^{\lambda}}\right] \\
& \left.=-\frac{1}{\rho} \lim _{\Delta R \rightarrow 0} \frac{\left[1-p(R)+p(R) e^{\lambda}\right]\left[-p^{\prime}(R+\Delta R)+p^{\prime}(R+\Delta R) e^{\lambda}\right.}{(A}\right]_{A} \\
& =-\frac{p^{\prime}(R)}{\rho} \frac{e^{\lambda}-1}{1+p(R)\left(e^{\lambda}-1\right)} .
\end{aligned}
$$

ad (i). Rearranging Result (30), and using Result (22), immediately yields Result (31). ad (ii). Expression (A.76) for $T E V$ is non-negative for all $R$, since $-p^{\prime}(R)$ is nonnegative and the term $\left(e^{\lambda}-1\right)$ is strictly positive for all $R$. Hence, Result (32) holds.

\section{References}

Arrow, K.J. (1965). Aspects of the theory of risk-bearing. Yrjö Jahnsson Lecture.

Reprinted with modifications in K.J. Arrow, Essays in the Theory of Risk Bearing, Markham, Chicago, 1971.

Baumgärtner, S. (2007). The insurance value of biodiversity in the provision of ecosystem services. Natural Resource Modeling, 20(1): 87-127.

Baumgärtner, S. and M.F. Quaas (2008). Agro-biodiversity as natural insurance and the development of financial insurance markets, In A. Kontoleon, U. Pascual and M. Smale (eds), Agrobiodiversity, Conservation and Economic Development, Routledge, London, pp. 293-317.

Besley, T. (1995). Savings, credit and insurance, In H.B. Chenery and T.N. Srinivasan (eds), Handbook of Development Economics, Vol. III, North Holland, Amsterdam, pp. 2123-2207. 
Brand, F. S., and K. Jax (2007). Focusing the meaning(s) of resilience: resilience as a descriptive concept and a boundary object. Ecology and Society, 12(1): 23.

Caillaud, B., G. Dionne and B. Jullien (2000). Corporate insurance with optimal financing contracts. Economic Theory, 16: 77-105.

Carpenter, S.R., B. Walker, J.M. Anderies and N. Abel (2001). From metaphor to measurement: resilience of what to what? Ecosystems, 4: 765-781.

Dasgupta, P. (1993). An Inquiry into Well-Being and Destitution. Clarendon Press, Oxford.

Dasgupta, P. and K.-G. Mäler (eds) (2003). The economics of non-convex ecosystems. Special issue, Environmental and Resource Economics, 26(4).

Ehrlich, J. and G.S. Becker (1972). Market insurance, self-insurance and self-protection. Journal of Political Economy, 80: 623-648.

Folke, C., S. Carpenter, T. Elmqvist, L. Gunderson, C. S. Holling, B. Walker, J. Bengtsson, F. Berkes, J. Colding, K. Danell, M. Falkenmark, L. Gordon, R. Kasperson, N. Kautsky, A. Kinzig, S. Levin, K.-G. Mäler, F. Moberg, L. Ohlsson, P. Olsson, E. Ostrom, W. Reid, J. Rockström, H. Savenije, and U. Svedin (2002). Resilience and sustainable development: building adaptive capacity in a world of transformations. Scientific Background Paper on Resilience for the process of The World Summit on Sustainable Development on behalf of The Environmental Advisory Council to the Swedish Government.

Freeman III, A.M. (2003). The Measurement of Environmental and Resource Values. Theory and Methods. Second edition. Resources for the Future, Washington DC.

Gravelle, H. and R. Rees (2004). Microeconomics. Third edition. Prentice Hall, Harlow. Gunderson, L.H. and L. Pritchard Jr. (eds) (2002). Resilience and the Behavior of Large-Scale Systems. Island Press, Washington DC. 
Hicks, J.R. (1943). The four consumer surpluses. Review of Economic Studies, 11(1): $31-41$.

Holling, C.S. (1973). Resilience and stability of ecological systems. Annual Review of Ecology and Systematics, 4: 1-23.

Holling, C.S., S. Carpenter, W.A. Brock and L.H. Gunderson (2002). Discoveries for sustainable futures. In L.H. Gunderson and C.S. Holling (eds), Panarchy. Understanding Transformations in Human and Natural Systems, Island Press, Washington DC, pp. 395-418.

Hunter, G. (2009). Noah's nonconcavity: on the existence of nontrivial interior solutions to the problem of cost-effective conservation planning. Natural Resource Modeling, 22: $26-41$.

Kataoka, S. (1963). A stochastic programming model. Econometrica, 31: 181-196.

Knight, F. (1921). Risk, Uncertainty and Profit. Houghton Mifflin, Boston.

Kreps, D.M. (1990). A Course in Microeconomic Theory. Harvester Wheatsheaf, New York.

Levin, S.A., S. Barrett, S. Aniyar, W. Baumol, C. Bliss, B. Bolin, P. Dasgupta, P. Ehrlich, C. Folke, I.-M. Gren, C.S. Holling, A.-M. Jansson, B.-O. Jansson, D. Martin, K.-G. Mäler, C. Perrings and E. Sheshinsky (1998). Resilience in natural and socioeconomic systems, Environment and Development Economics, 3(2): 222-234.

Mäler, K.-G. (2008). Sustainable development and resilience in ecosystems. Environmental and Resource Economics, 39(1): 17-24.

Mäler, K.-G., S. Aniyar and A. Jansson (2009). Accounting for ecosystems. Environmental and Resource Economics, 42(1): 39-51.

Mäler, K.-G., C.-Z. Li and G. Destouni (2007). Pricing resilience in a dynamic economyenvironment system: a capital-theoretic approach. Beijer Discussion Paper No. 208 (available at http://www.beijer.kva.se/discussions.php). 
Mayers, D. and C.W. Smith Jr. (1990). On the corporate demand for insurance: evidence from the reinsurance market. Journal of Business, 63(1): 19-40.

McCall, J.J. (1987). Insurance. In J. Eatwell, M. Milgate and P. Newman (eds), The New Palgrave. A Dictionary of Economics, Volume 2, Palgrave, Houndmills, pp. 868-870.

Perrings, C. (1995). Biodiversity conservation as insurance. In T. Swanson (ed.), The Economics and Ecology of Biodiversity Decline, Cambridge University Press, Cambridge, pp. 69-77.

Perrings, C. und D.I. Stern (2000). Modelling loss of resilience in agroecosystems: rangelands in Botswana. Environmental and Resource Economics, 16: 185-210.

Perrings, C. und B.W. Walker (1995). Biodiversity loss and the economics of discontinuous change in semiarid rangelands. In: C. Perrings, K.-G. Mäler, C. Folke, C.S. Holling und B.-O. Jansson (eds), Biodiversity Loss. Economic and Ecological Issues, Cambridge University Press, Cambridge, pp. 190-210.

Quaas, M.F. and S. Baumgärtner (2008). Natural vs. financial insurance in the management of public-good ecosystems. Ecological Economics, 65(2): 397-406.

Pratt, J.W. (1964). Risk aversion in the small and in the large. Econometrica, 32(1-2): $122-136$.

Radner, R. and J.E. Stiglitz (1984). A nonconcavity in the value of information. In M. Boyer and R.E. Kihlstrom (eds), Bayesian models in economic theory, North-Holland, New York, pp. 33-52.

Roy, A.D. (1952). Safety first and the holding of assets. Econometrica, 20(3): 431-449.

Scheffer, M., S. Carpenter, J.A. Foley, C. Folke and B. Walker (2001). Catastrophic shifts in ecosystems. Nature, 413: 591-596.

Telser, L.G. (1955). Safety first and hedging. The Review of Economic Studies, 23: $1--16$. 
[UNCCD] Secretariat of the United Nations Convention to Combat Desertification (2005). Fact Sheet 3 - The Consequences of Desertification. http://www.unccd.int.

[UNO] United Nations Organisation (2002). United Nations Convention to Combat Desertification. http://www.unccd.int.

Varian, H.R. (1992). Microeconomic Analysis. 3rd ed., W.W. Norton, New York and London.

Walker, B., L. Pearson, M. Harris, K.-G. Mäler, C.-Z. Li and R. Biggs (2007). Incorporating resilience in the assessment of inclusive wealth: an example from South East Australia. Beijer Discussion Paper No. 209 (available at http://www.beijer.kva.se/discussions.php). 


\section{Working Paper Series in Economics}

(recent issues)

No.131: Matthias Schröter, Oliver Jakoby, Roland Olbrich, Marcus Eichhorn and Stefan Baumgärtner: Remote sensing of bush encroachment on commercial cattle farms in semi-arid rangelands in Namibia, July 2009

No.130: Nils Braakmann: Other-regarding preferences, spousal disability and happiness: Evidence for German Couples, May 2009

No.129: Alexander Vogel and Joachim Wagner: Exports and Profitability - First Evidence for German Services Enterprises, May 2009

No.128: Sebastian Troch: Drittelbeteiligung im Aufsichtsrat - Gesetzliche Regelung versus Unternehmenspraxis. Ausmaß und Bestimmungsgründe der Umgehung des Drittelbeteiligungsgesetzes in Industrieunternehmen, Mai 2009

No.127: Alexander Vogel: The German Business Services Statistics Panel 2003 to 2007, May 2009

[forthcoming in: Schmollers Jahrbuch 129 (2009)]

No.126: Nils Braakmann: The role of firm-level and regional human capital fort he social returns to education - Evidence from German social security data, April 2009

No.125: Elke Bertke und Markus Groth: Angebot und Nachfrage nach Umweltleistungen in einem marktanalogen Agrarumweltprogramm - Ergebnisse einer Pilotstudie, April 2009

No.124: Nils Braakmann and Alexander Vogel: The impact of the 2004 EU-enlargement on enterprise performance and exports of service enterprises in the German eastern border region, April 2009

No.123: Alexander Eickelpasch and Alexander Vogel: Determinants of Export Behaviour of German Business Services Companies, March 2009

No.122: Maik Heinemann: Stability under Learning of Equilibria in Financial Markets with Supply Information, March 2009

No.121: Thomas Wein: Auf der Speisekarte der DPAG: Rechtliche oder ökonomische Marktzutrittsschranken? März 2009

No.120: Nils Braakmann und Joachim Wagner: Product Diversification and Stability of Employment and Sales: First Evidence from German Manufacturing Firms, February 2009

No.119: Markus Groth: The transferability and performance of payment-by-results biodiversity conservation procurement auctions: empirical evidence from northernmost Germany, February 2009

No.118: Anja Klaubert: Being religious - A Question of Incentives? February 2009

No.117: $\quad$ Sourafel Girma, Holger Görg and Joachim Wagner: Subsidies and Exports in Germany. First Evidence from Enterprise Panel Data, January 2009

No.116: Alexander Vogel und Joachim Wagner: Import, Export und Produktivität in niedersächsischen Unternehmen des Verarbeitenden Gewerbes, Januar 2009

No.115: Nils Braakmann and Joachim Wagner: Product Differentiation and Profitability in German Manufacturing Firms, January 2009

No.114: Franziska Boneberg: Die Drittelmitbestimmungslücke im Dienstleistungssektor: Ausmaß und Bestimmungsgründe, Januar 2009

No.113: Institut für Volkswirtschaftslehre: Forschungsbericht 2008, Januar 2009 
No.112: Nils Braakmann: The role of psychological traits and the gender gap in full-time employment and wages: Evidence from Germany. January 2009

No.111: $\quad$ Alexander Vogel: Exporter Performance in the German Business Services Sector: First Evidence from the Services Statistics Panel. January 2009 [revised version forthcoming in: The Service Industries Journal]

No.110: $\quad$ Joachim Wagner: Wer wird subventioniert? Subventionen in deutschen Industrieunternehmen 1999 - 2006. Januar 2009

No.109: $\quad$ Martin F. Quaas, Stefan Baumgärtner, Sandra Derissen, and Sebastian Strunz: Institutions and preferences determine resilience of ecological-economic systems. December 2008

No.108: $\quad$ Maik Heinemann: Messung und Darstellung von Ungleichheit. November 2008

No.107: $\quad$ Claus Schnabel \& Joachim Wagner: Union Membership and Age: The inverted U-shape hypothesis under test. November 2008

No.106: $\quad$ Alexander Vogel \& Joachim Wagner: Higher Productivity in Importing German Manufacturing Firms: Self-selection, Learning from Importing, or Both?

November 2008

[revised version forthcoming in: Review of World Economics]

No.105: $\quad$ Markus Groth: Kosteneffizienter und effektiver Biodiversitätsschutz durch Ausschreibungen und eine ergebnisorientierte Honorierung: Das Modellprojekt „Blühendes Steinburg“. November 2008

No.104: $\quad$ Alexander Vogel \& Joachim Wagner: Export, Import und Produktivität wissensintensiver KMUs in Deutschland. Oktober 2008

No.103: $\quad$ Christiane Clemens \& Maik Heinemann: On Entrepreneurial Risk - Taking and the Macroeconomic Effects Of Financial Constraints, October 2008

No.102: $\quad$ Helmut Fryges \& Joachim Wagner: Exports and Profitability - First Evidence for German Manufacturing Firms. October 2008

No.101: $\quad$ Heike Wetzel: Productivity Growth in European Railways: Technological Progress, Efficiency Change and Scale Effects. October 2008

No.100: Henry Sabrowski: Inflation Expectation Formation of German Consumers: Rational or Adaptive? October 2008

No.99: Joachim Wagner: Produktdifferenzierung in deutschen Industrieunternehmen 1995 - 2004: Ausmaß und Bestimmungsgründe, Oktober 2008

No.98: Jan Kranich: Agglomeration, vertical specialization, and the strength of industrial linkages, September 2008

No.97: Joachim Wagner: Exports and firm characteristics - First evidence from Fractional Probit Panel Estimates, August 2008

No.96: Nils Braakmann: The smoking wage penalty in the United Kingdom: Regression and matching evidence from the British Household Panel Survey, August 2008

No.95: Joachim Wagner: Exportaktivitäten und Rendite in niedersächsischen Industrieunternehmen, August 2008

[publiziert in: Statistische Monatshefte Niedersachsen 62 (2008), 10,552-560]

No.94: Joachim Wagner: Wirken sich Exportaktivitäten positiv auf die Rendite von deutschen Industrieunternehmen aus?, August 2008

[publiziert in: Wirtschaftsdienst, 88 (2008) 10, 690-696] 
No.93:

Claus Schnabel \& Joachim Wagner: The aging of the unions in West Germany, 1980-2006, August 2008

[forthcoming in: Jahrbücher für Nationalökonomie und Statistik]

No.92: $\quad$ Alexander Vogel and Stefan Dittrich: The German turnover tax statistics panels, August 2008

[published in: Schmollers Jahrbuch 128 (2008), 4, 661-670]

No.91: Nils Braakmann: Crime does pay (at least when it's violent!) - On the compensating wage differentials of high regional crime levels, July 2008

No.90: $\quad$ Nils Braakmann: Fields of training, plant characteristics and the gender wage gap in entry wages among skilled workers - Evidence from German administrative data, July 2008

No.89: $\quad$ Alexander Vogel: Exports productivity in the German business services sector: First evidence from the Turnover Tax Statistics panel, July 2008

No.88: Joachim Wagner: Improvements and future challenges for the research infrastructure in the field Firm Level Data, June 2008

No.87: $\quad$ Markus Groth: A review of the German mandatory deposit for one-way drinks packaging and drinks packaging taxes in Europe, June 2008

No.86: $\quad H e i k e$ Wetzel: European railway deregulation. The influence of regulatory ans environmental conditions on efficiency, May 2008

No.85: $\quad$ Nils Braakmann: Non scholae, sed vitae discimus! - The importance of fields of study for the gender wage gap among German university graduates during market entry and the first years of their careers, May 2008

No.84: $\quad$ Markus Groth: Private ex-ante transaction costs for repeated biodiversity conservation auctions: A case study, May 2008

No.83: $\quad$ Jan Kranich: R\&D and the agglomeration of industries, April 2008

No.82: $\quad$ Alexander Vogel: Zur Exporttätigkeit unternehmensnaher Dienstleister in Niedersachsen - Erste Ergebnisse zu Export und Produktivität auf Basis des Umsatzsteuerstatistikpanels, April 2008

No.81: Joachim Wagner: Exporte und Firmenerfolg: Welche Firmen profitieren wie vom internationalen Handel?, März 2008

No.80: $\quad$ Stefan Baumgärtner: Managing increasing environmental risks through agrobiodiversity and agri-environmental policies, March 2008

No.79: $\quad$ Thomas Huth: Die Quantitätstheorie des Geldes - Eine keynesianische Reformulierung, März 2008

No.78: $\quad$ Markus Groth: An empirical examination of repeated auctions for biodiversity conservation contracts, March 2008

No.77: Nils Braakmann: Intra-firm wage inequality and firm performance - First evidence from German linked employer-employee-data, February 2008

No.76: $\quad$ Markus Groth: Perspektiven der Nutzung von Methanhydraten als Energieträger Eine Bestandsaufnahme, Februar 2008

(see www.leuphana.de/vwl/papers for a complete list) 
Leuphana Universität Lüneburg

Institut für Volkswirtschaftslehre

Postfach 2440

D-21314 Lüneburg

Tel.: ++49 41316772321

email: brodt@leuphana.de

www.leuphana.de/vwl/papers 